\title{
Thermodynamics of Partitioning of Benzocaine in Some Organic Solvent/Buffer and Liposome Systems
}

\author{
Carolina Mercedes Ávila and Fleming Martínez* \\ Department of Pharmacy, National University of Colombia; A.A. 14490, Bogotá D.C., Colombia. \\ Received August 8, 2002; accepted November 7, 2002
}

\begin{abstract}
The thermodynamics of partitioning of benzocaine (BZC) were studied in octanol/buffer (ROH/W), isopropyl myristate/buffer (IPM/W), cyclohexane/buffer (CH/W), and dimyristoyl phosphatidylcholine (DMPC) and dipalmitoyl phosphatidylcholine (DPPC) liposome systems. In all cases the partition coefficients were greater than unity; therefore the free energies of transfer were negative, that is, the processes of transfer of BZC from aqueous media to organic systems were spontaneous. The partition coefficients were approximately three-fold higher in DMPC liposomes compared with the ROH/W system in the $30^{\circ}-40^{\circ} \mathrm{C}$ temperature range. The enthalpies of transfer from aqueous media to $\mathrm{ROH}$ and IPM were negative, but positive for $\mathrm{CH}$, while this property was negative for DMPC liposomes and positive for DPPC liposomes. The entropies of transfer were positive in almost all cases, except for DMPC. The results presented here confirm the lipophilic nature of BZC.
\end{abstract}

Key words partitioning; thermodynamic; partition coefficient; benzocaine; liposome

Some local anesthetics are poorly soluble in water and consequently too slowly absorbed to be toxic. They can be applied directly to wounds and ulcerated surfaces, where they remain localized for long periods of time and produce a sustained anesthetic action. The most important member of these compounds is benzocaine (BZC), ethyl $p$-aminobenzoate. It is incorporated into a large number of topical preparations for the relief of pain and pruritis. ${ }^{1)}$

Extensive studies have shown that anesthetic potency is closely related to the partition coefficient of the drug. These observations have suggested mechanisms of action based on perturbation of membrane lipids. ${ }^{2)}$ Local anesthetics drugs due to their amphiphilic structure show strong interactions with phospholipids. These interactions can be characterized by thermoanalytical studies as well as by computational graphics. ${ }^{3)}$

The general observation that the more hydrophobic local anesthetics are more potent nerve blockers has been incorporated quantitatively in biophysical models of anesthetic action. Attempts have been made previously to simulate biomembranes using a simple solvent system, such as octanol, studying the partitioning of solutes in front to water. Partition coefficients provide information on the hydrophobic nature of the compounds and their potential for interactions within various regions of bilayer membranes. ${ }^{4)}$

An important physical process common to all systems in which a solute is transported from a high-concentration aqueous phase across an organic membrane barrier into a low-concentration aqueous phase is the interfacial transfer of the substrate at the aqueous-organic and organic-aqueous interfaces. ${ }^{5)}$ Before we can understand the chemistry of the transfer process in membranes, we must characterize the behavior in simpler systems. $\left.{ }^{6}\right)$ There is no agreement on which organic solvent best simulates the hydrophilic-hydrophobic nature of the biological membrane. Some researchers have preferred to study the correlation between anesthetic potency and anesthetic partitioning into a monolayer/water system. ${ }^{7}$

The thermodynamics of transfer of drug molecules can be studied by measuring the partition coefficient as a function of temperature. Such data can be used for the prediction of ab- sorption, membrane permeability, and in vivo drug distribution. ${ }^{8)}$ Semipolar solvents have been found to yield better correlations with partitioning of solutes in model membranes compared with nonpolar solvents such as cyclohexane. In particular, octanol has been found to be a useful reference solvent for extrathermodynamic studies in a variety of systems ${ }^{9-11)}$ although isopropyl myristate (IPM) also has been used. ${ }^{12)}$ IPM has been used to determine hydrophobic constants because it most closely simulates the stratum corneumwater partition. ${ }^{13)}$ IPM is best related to skin/transdermal absorption because its polar and nonpolar nature mimics the complex nature (polar/nonpolar matrix) of the skin. ${ }^{14)}$ However, the octanol/water system is a poor model system for several drug transport processes and for the correlation among pharmacokinetic parameters. On the other hand, the liposome system has been shown to discriminate against branched solutes more than a bulk oil/water system in the case of some phenols, ${ }^{15,16)}$ phenotiazines, ${ }^{17,18)}$ beta-blockers, ${ }^{19)}$ and nonsteroidal anti-inflammatory drugs. ${ }^{8)}$ In addition the partitioning was higher in liposomes than in octanol for dipyridamole ${ }^{20)}$ mefloquine, quinine, and other antimalarial drugs. $^{21,22)}$

The objective of this study was to compare the partitioning behavior of BZC in octanol/buffer ( $\mathrm{ROH} / \mathrm{W})$, isopropyl myristate/buffer (IPM/W), cyclohexane/buffer $(\mathrm{CH} / \mathrm{W})$, and dimyristoyl phosphatidylcholine (DMPC/W) and dipalmitoyl phosphatidylcholine (DPPC/W) liposome systems, using a thermodynamic approach based on the variation of partitioning with temperature.

\section{Experimental}

Materials and Equipment BZC, DMPC (ref P-7331), and DPPC (ref P-5911) were obtained from Sigma Chemical Co. Octanol extra pure (ROH), isopropyl myristate F.S. (IPM), and cyclohexane F.A. (CH) were purchased from Merck, distilled water (W) (conductivity $<2 \mu \mathrm{S}$ ) from the Laboratory of Industrial Pharmacy, chloroform A.R. from Mallinckrodt, and potassium chloride A.R. and sodium mono- and dihydrogen phosphates A.R. from Merck.

Magni Whirl Blue M. Electric Company water baths, a Wrist Action Burrel model 75 mechanical shaker, a Mistral ${ }^{\mathbb{B}}$ model 1192 vortex mixer, a Buchler Instruments evaporator, a WTB Binder E28 sterilizer/drying oven, a Biofuge 15R Heraeus Instruments centrifuge, a Zeiss ICS Kf 2 optic micro- 
scope, a Mettler AE 160 digital analytical balance (sensitivity $0.1 \mathrm{mg}$ ), an Unicam UV/Vis UV2-100 v 4.00 spectrophotometer, and Nichiryo ${ }^{\circledR}$ micropipettes were used.

Organic Solvent/Buffer Partitioning Both solvents were mutually saturated before performing the experiments. Solutions of BZC of known concentration, about $10^{-4} \mathrm{~mol} / 1$, were prepared in aqueous buffer solution, adjusted to $\mathrm{pH} 7.4$ at ionic strength of $0.15 \mathrm{~mol} / 1$. Then $5.0 \mathrm{ml}$ of ROH or IPM was added to $25.0 \mathrm{ml}$ of the aqueous BZC solution in glass flasks; in the case of $\mathrm{CH} / \mathrm{W}$ partitioning, $10.0 \mathrm{ml}$ of $\mathrm{CH}$ and $20.0 \mathrm{ml}$ of aqueous drug solution were employed. All aliquots were weighted. The mixtures were then stirred in a mechanical shaker for $1 \mathrm{~h}$. Samples were allowed to stand in water baths kept at the appropriate temperature $\left( \pm 0.1^{\circ} \mathrm{C}\right)$ for at least $48 \mathrm{~h}$. After this time the aqueous phases were isolated and the BZC concentrations were determined by measuring the UV absorbances and interpolating from previously constructed calibration curves. ${ }^{23)}$ The partition coefficients were calculated based on mass balance. All the partitioning experiments were repeated at least three times and averaged.

Liposome/Buffer Partitioning Liposomes were prepared by a modified Bangham method. ${ }^{24)}$ Thin films of $50 \mathrm{mg}$ of DMPC or DPPC were formed on the walls of 50-ml round-bottomed flasks following rotary evaporation of $5 \mathrm{ml}$ aliquots of a chloroform solution. Then the flasks were placed in an oven at $40^{\circ} \mathrm{C}$ for $24 \mathrm{~h}$. The films were dispersed in $5 \mathrm{ml}$ of aqueous drug solution (the same as used in the octanol/buffer partitioning), heated at $30^{\circ}$ or $45^{\circ} \mathrm{C}$, and vortex-mixed until all the film was removed from the walls of the flasks. ${ }^{25)}$ This resulted in the formation of multilamellar vesicles (MLVs), which was verified by microscopy according to reported methods. ${ }^{26)}$ The drug distribution was determined in $48 \mathrm{~h}$ temperature-equilibrated MLVs in $1.2 \mathrm{ml}$ samples, followed by centrifugation $(25000 \mathrm{~g}$ for $60 \mathrm{~min})$ at the specified temperature, from UV analysis and mass balance calculations over the range of $25^{\circ}$ to $40^{\circ} \mathrm{C}$. All the partitioning experiments were repeated at least three times and averaged.

Determination of Partition Coefficients and Thermodynamic Functions of Transfer The molal partition coefficients $(K)$, were calculated using Eq. 1.

$$
K=W_{\text {aq }}\left(C_{0}-C_{\mathrm{f}}\right) /\left(C_{\mathrm{f}} W_{\text {org }}\right)
$$

where $C_{0}$ and $C_{\mathrm{f}}$ are the initial and final concentrations of BZC $(\mu \mathrm{g} / \mathrm{ml})$ in the aqueous buffer phase before and after equilibration, respectively, $W_{\mathrm{aq}}$ the weight $(\mathrm{g})$ of the aqueous phase, and $W_{\text {org }}$ the weight $(\mathrm{g})$ of organic solvent or phospholipid in the sample.

The standard free energy of transfer $\left(\Delta G_{\mathrm{w} \rightarrow \mathrm{o}}\right)$, from aqueous media to organic systems was calculated using Eq. 2.

$$
\Delta G_{\mathrm{w} \rightarrow \mathrm{0}}=-R T \ln K
$$

where $K$ is expressed in molality.

The temperature dependence of partitioning (van't Hoff method) was employed to obtain data on the enthalpy of transfer $\left(\Delta H_{\mathrm{w} \rightarrow \mathrm{o}}\right)$, based on Eq. 3, assuming that $\Delta H_{\mathrm{w} \rightarrow \mathrm{o}}$ is approximately independent of temperature over the range of interest. The values $\Delta H_{\mathrm{w} \rightarrow 0}$ were obtained from the slopes of $\ln K$ versus $T^{-1}$ weighted curves, obtained using linear regression with the leastsquares method.

$$
\Delta H_{\mathrm{w} \rightarrow \mathrm{o}}=R[\partial(-\ln K) / \partial(1 / T)]_{P}
$$

The entropy of transfer $\left(\Delta S_{\mathrm{w} \rightarrow 0}\right)$, was obtained from Eq. 4 , assuming that this property does not change with temperature in the range studied.

$$
\Delta S_{\mathrm{w} \rightarrow \mathrm{o}}=\left(\Delta H_{\mathrm{w} \rightarrow \mathrm{o}}-\Delta G_{\mathrm{w} \rightarrow \mathrm{o}}\right) / T
$$

$\Delta H_{\mathrm{w} \rightarrow \mathrm{o}}$ and $\Delta S_{\mathrm{w} \rightarrow \mathrm{o}}$ represent the change in enthalpy and entropy, respectively, when $1 \mathrm{~mol}$ of BZC is transferred from the aqueous medium to the organic system at infinite dilution expressed in molality.

\section{Results and Discussion}

Physicochemical Properties of BZC The molecular structure and some physicochemical properties of BZC are summarized in Table 1 . The $\mathrm{p} K_{\mathrm{a}}$ was corrected to ionic strength of $\mu=0.15 \mathrm{~mol} / 1$, similar to that of the gastrointestinal tract, ${ }^{27)}$ by means of the Debye-Hückel equation. ${ }^{28)}$ Since the partitioning of $\mathrm{BZC}$ is $\mathrm{pH}$ dependent (BZC is a basic compound), this property was determined at $\mathrm{pH} 7.4$ (physiological value $\mathrm{e}^{29)}$ ). At this $\mathrm{pH}, \mathrm{BZC}$ has their largest partitioning because the molecular compound without dissociation dominates. ${ }^{30)}$ The $\mathrm{pH}$ value was regulated with phosphate buffer having $\beta$ capacity of 0.01 using $\mathrm{p} K_{\mathrm{a}}$ values corrected to $\mu=0.15 \mathrm{~mol} / 1$.

Partition Coefficients Table 2 summarizes the temperature dependence of the partition coefficients for BZC in all systems (molality). The $K$ values diminish with rising temperature for $\mathrm{BZC}$ in $\mathrm{ROH} / \mathrm{W}$, IPM/W, and $\mathrm{DMPC} / \mathrm{W}$ (over $30{ }^{\circ} \mathrm{C}$ ), but increase for $\mathrm{BZC}$ in $\mathrm{CH} / \mathrm{W}$ and $\mathrm{DPPC} / \mathrm{W}$. The partitioning was the greatest for $\mathrm{BZC}$ in $\mathrm{DMPC} / \mathrm{W}$ at $30^{\circ} \mathrm{C}$ and the lowest for $\mathrm{BZC}$ in $\mathrm{CH} / \mathrm{W}$ at $25^{\circ} \mathrm{C}$.

By comparing our $K_{\mathrm{ROH} / \mathrm{w}}$ values with those reported in the literature, the values at $25^{\circ} \mathrm{C}$ are almost equal to that found by Strichartz et al. ${ }^{6}$ but at $35^{\circ} \mathrm{C}$, the values are very different. On the other hand, the value presented by Pinto et al. ${ }^{32}$ ) is not coincident with our values.

The temperature dependence of partitioning for BZC in all systems, as $\ln K$ versus $T^{-1}$ (van't Hoff plots) is presented in Figs. 1 to 3. In all cases (except for DPPC/W), straight lines with correlation coefficients $(r)$ near 0.95 were obtained for the partitioning systems evaluated; therefore the van't Hoff method is useful for the respective thermodynamic analyses. ${ }^{33)}$ For $K_{\mathrm{DPPC} / \mathrm{w}}$, a quadratic model for regression was obtained (Fig. 3). In the DMPC/W partitioning (Fig. 3) the value at $25^{\circ} \mathrm{C}(93 \pm 5)$ was not considered in the van't Hoff analysis because it does not follows the same behavior as that exhibited by the other values. To understand this apparent anomalous behavior, it will be necessary to perform an

Table 1. Some Physicochemical Properties of BZC

\begin{tabular}{ccccc}
\hline \hline Abbrev. & Molecular structure & $\mathrm{MW}^{a)}$ & $\mathrm{p} K_{\mathrm{a}}^{b)}$ & $\lambda_{\max }^{a, c)}$ \\
\hline $\mathrm{BZC}$ & $\mathrm{H}_{2} \mathrm{~N}$
\end{tabular}

a) Unites: molecular weight $(\mathrm{g} / \mathrm{mol})$ and $\lambda_{\max }(\mathrm{nm})$. b) Corrected to $\mu=0.15 \mathrm{~mol} / 1$

\begin{tabular}{|c|c|c|c|c|}
\hline \multirow{2}{*}{$\begin{array}{l}\text { Partitioning } \\
\text { system }\end{array}$} & \multicolumn{4}{|c|}{ Temperature $\left({ }^{\circ} \mathrm{C}\right)$} \\
\hline & 25.0 & 30.0 & 35.0 & 40.0 \\
\hline$K_{\mathrm{ROH} / \mathrm{W}}$ & $90.2(0.5)$ & $88.0(0.5)$ & $84.8(0.7)$ & $81.8(0.4)$ \\
\hline$K_{\mathrm{CH} / \mathrm{W}}$ & $1.88(0.04)$ & $2.048(0.020)$ & $2.21(0.07)$ & $2.464(0.026)$ \\
\hline$K_{\mathrm{IPM} / \mathrm{W}}$ & $35.9(0.6)$ & $33.7(0.6)$ & $31.9(0.5)$ & $30.44(0.14)$ \\
\hline$K_{\mathrm{DMPC} / \mathrm{W}}$ & $93(5)$ & $248(9)$ & $224(5)$ & $202(6)$ \\
\hline$K_{\mathrm{DPPC} / \mathrm{W}}$ & $3.32(0.08)$ & $9.91(0.10)$ & $30.5(0.9)$ & $43.6(0.8)$ \\
\hline
\end{tabular}
using the Debye-Hückel equation. ${ }^{28,31}$ c) Value in water at $\mathrm{pH} 7.4$ and $\mu=0.15 \mathrm{~mol} / \mathrm{l}$.

Table 2. Partition Coefficients of BZC in Several Systems as a Function of Temperature $\left( \pm 0.1^{\circ} \mathrm{C}\right)$, in Molality ( \pm Standard Deviation)

$K_{\mathrm{ROH} / \mathrm{w}}$ : octanol/buffer (pH 7.4, $\mu=0.15 \mathrm{~mol} / \mathrm{l}$ ) partitioning. $K_{\mathrm{CH} / \mathrm{w}}$ : cyclohexane/ buffer partitioning. $K_{\mathrm{IPM} / \mathrm{W}}$ : isopropyl myristate/buffer partitioning. $K_{\mathrm{DMPC} / \mathrm{W}}$ : DMPC liposome/buffer partitioning. $K_{\mathrm{DPPC} / \mathrm{W}}$ : DPPC liposome/buffer partitioning.

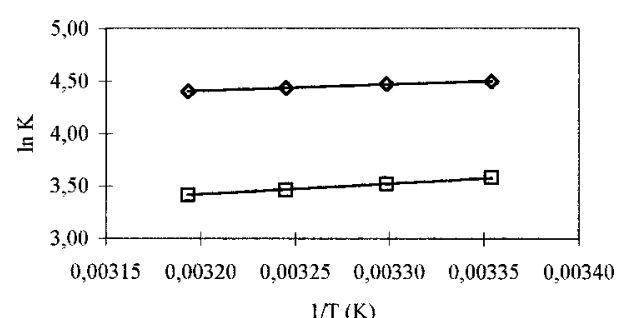

Fig. 1. Partitioning-Temperature Dependence for BZC in Octanol/Buffer (Rhombic) and Isopropyl Myristate/Buffer (Squares) Systems 
analysis of the liposomal dispersion by means of differential scanning calorimetry to evaluate possible increases in the transition temperature $(T c)$, because the $K_{\mathrm{DMPC} / \mathrm{W}}$ at $25^{\circ} \mathrm{C}$ is similar in order to those obtained for DPPC/W partitioning; that is, liposomes are in a gel state (rigid state), where the partitioning is lower than those obtained in fluid liposomes such as DMPC/W.

Thermodynamic Aspects of Transfer Table 3 summarizes the thermodynamic functions related to the transfer of BZC from aqueous media to organic systems (octanol, isopropyl myristate, cyclohexane, and DMPC or DPPC liposomes). In all cases, $\Delta G_{\mathrm{w} \rightarrow \mathrm{o}}$ at $25^{\circ} \mathrm{C}$ is negative, the transfer BZC from aqueous media to organic systems is thus spontaneous, and the magnitudes of these properties are also proportional to the degree of lipophilicity. The enthalpies of transfer $\left(\Delta H_{\mathrm{w} \rightarrow \mathrm{o}}\right)$ of BZC are negative for $\mathrm{ROH} / \mathrm{W}, \mathrm{IPM} / \mathrm{W}$,

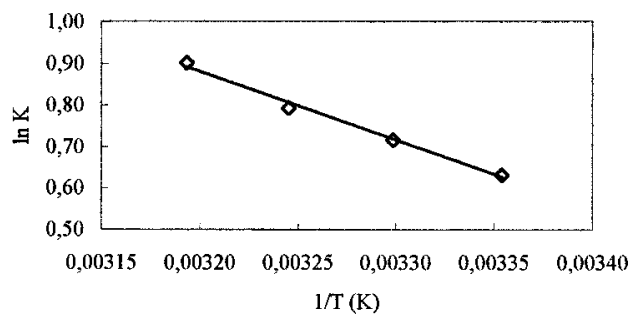

Fig. 2. Partitioning-Temperature Dependence for BZC in Cyclohexane/Buffer System

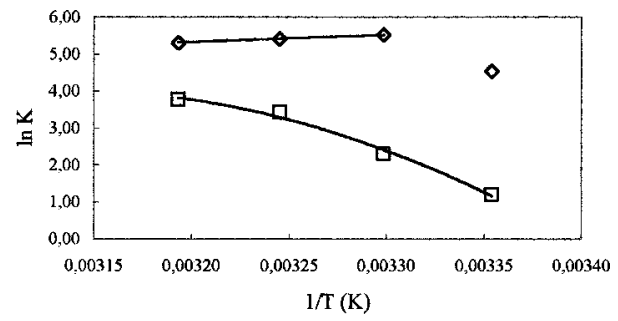

Fig. 3. Partitioning-Temperature Dependence for BZC in DMPC (Rhombic) and DPPC (Squares) Liposome Systems

Table 3. Free Energy, Enthalpy, and Entropy for the Transfer of BZC from Aqueous Media to Several Organic Systems, in Molality ( \pm Standard Deviation) $\left(\Delta G_{\mathrm{w} \rightarrow \mathrm{o}}\right.$ and $\Delta S_{\mathrm{w} \rightarrow \mathrm{o}}$ at $\left.25.0 \pm 0.1^{\circ} \mathrm{C}\right)$

\begin{tabular}{cccc}
\hline \hline Partitioning system & $\Delta G_{\mathrm{w} \rightarrow \mathrm{o}}(\mathrm{kJ} / \mathrm{mol})$ & $\Delta H_{\mathrm{w} \rightarrow \mathrm{o}}(\mathrm{kJ} / \mathrm{mol})$ & $\Delta S_{\mathrm{w} \rightarrow \mathrm{o}}(\mathrm{J} / \mathrm{mol} / \mathrm{K})$ \\
\hline$K_{\mathrm{ROH} / \mathrm{W}}$ & $-11.159(0.013)$ & $-5.11(0.28)$ & $20.3(0.9)$ \\
$K_{\mathrm{CH} / \mathrm{W}}$ & $-1.57(0.05)$ & $13.7(0.8)$ & $51.1(2.8)$ \\
$K_{\mathrm{IPM} / \mathrm{W}}$ & $-8.88(0.04)$ & $-8.6(0.5)$ & $1.08(1.8)$ \\
$K_{\mathrm{DMPC} / \mathrm{W}}$ & $-11.25(0.14)$ & $-16.3(1.8)$ & $-7.80(6)^{a)}$ \\
$K_{\mathrm{DPPC} / \mathrm{W}}$ & $-2.98(0.06)$ & $215(13)^{b)}$ & $732(44)$ \\
\hline
\end{tabular}

a) $\Delta S_{\mathrm{w} \rightarrow \mathrm{o}}$ at $30.0^{\circ} \mathrm{C}$ in $K_{\mathrm{DMPC} / \mathrm{W}}$. b) $\Delta H_{\mathrm{w} \rightarrow \mathrm{o}}$ at $25.0^{\circ} \mathrm{C}$ in $K_{\mathrm{DPPC} / \mathrm{W}}$. and DPMC/W (if the $K_{\mathrm{DMPC} / \mathrm{W}}$ value at $25^{\circ} \mathrm{C}$ is not considered), and positive for $\mathrm{CH} / \mathrm{W}$ and $\mathrm{DPPC} / \mathrm{W}$ (obtained at $25^{\circ} \mathrm{C}$ for DPPC from the first derivative of the respective polynomial function). Negative enthalpies indicate the presence of significant hydrogen bonding between molecules of BZC and ROH, IPM, and DMPC. ROH can establish hydrogen bonding as donor or acceptor of hydrogen, while IPM acts as an acceptor, that is, this compound is an ester (Lewis base). The entropies of transfer $\left(\Delta S_{\mathrm{w} \rightarrow 0}\right)$ are negative for $\mathrm{BZC}$ in DMPC, and positive for the other partitioning systems, indicating that the transfer of BZC is entropy driven in $\mathrm{CH} / \mathrm{W}$ and DPPC/W, while it is enthalpy driven in DMPC/W and enthalpy-entropy driven for $\mathrm{ROH} / \mathrm{W}$ and IPM/W.

By comparing our value for $\Delta H_{\mathrm{w} \rightarrow \mathrm{o}}$, in the $\mathrm{ROH} / \mathrm{W}$ system with that reported by Stritchartz et al., ${ }^{6}$ it is found that coincidence was not present, because according to our results the process of transfer is exothermic, i.e., $K_{\mathrm{ROH} / \mathrm{w}}$ values diminish with increasing temperature (Table 2), whereas Stritchartz et al. presented results that indicate endothermic behavior because $K_{\mathrm{ROH} / \mathrm{W}}$ increases from 81 at $25^{\circ} \mathrm{C}$ to 132 at $36^{\circ} \mathrm{C}$. $\left.{ }^{6}\right)$

The increase in entropy in the transfer of BZC to DPPC liposomes is probably due to the disorder produced in the hydrophobic core of the bilayers. In the temperature range studied $\left(25^{\circ}\right.$ to $\left.40^{\circ} \mathrm{C}\right)$, DMPC liposomes are in a liquid crystal (fluid) state, whereas DPPC liposomes are in a gel (rigid) state, because their transition temperatures, $T c$, are $23.6 \pm 1.5^{\circ} \mathrm{C}$ and $41.3 \pm 1.8^{\circ} \mathrm{C}$, respectively. ${ }^{34,35)}$ Therefore more energy is required for accommodation of $\mathrm{BZC}$ into DPPC bilayers than into DMPC bilayers. This may be attributed to the larger van der Waals interactions between hydrophobic tails in DPPC due to their length (two more methylene groups). In the same way, the entropy of transfer is greater in DPPC liposomes than in DMPC liposomes, due to larger disorder produced in separating the DPPC hydrophobic tails to accommodate the solute molecules compared with DMPC.

Parameter of Seiler and Other Analogous Parameters Seiler proposed Eq. 5 that compares the partition coefficients of drug in $\mathrm{ROH} / \mathrm{W}$ and $\mathrm{CH} / \mathrm{W}$ to obtain information related to the hydrogen bond contribution to the partitioning of solutes. $^{36)}$

$$
\Delta \log K_{\mathrm{ROH} / \mathrm{W}}=\log K_{\mathrm{ROH} / \mathrm{W}}-\log K_{\mathrm{CH} / \mathrm{W}}
$$

Equation 5 may be also written as a quotient relationship in the form $\Delta \log K_{\mathrm{ROH} / \mathrm{W}}=\log \left(K_{\mathrm{ROH} / \mathrm{W}} / K_{\mathrm{CH} / \mathrm{W}}\right)$, showing the hydrogen bond nature of the interactions between the drug and the solvents according to the specific value, that is, if $\Delta \log K_{\mathrm{ROH} / \mathrm{w}}>0$, then this result indicates some contribution by hydrogen bond to the partitioning. Table 4 presents the values of the parameter of Seiler and other analogous parameters for BZC at $30^{\circ} \mathrm{C}$, calculated from the different parti-

Table 4. Parameter of Seiler ${ }^{36)}$ and Other Analogous Parameters for $\mathrm{BZC}$ at $30.0^{\circ} \mathrm{C}$ in Molality

\begin{tabular}{|c|c|c|c|c|c|}
\hline Parameter & System 1 & System 2 & $\log K_{1}$ & $\log K_{2}$ & $\Delta \log K^{a)}$ \\
\hline$\Delta \log K_{\mathrm{ROH} / \mathrm{W}}=\log K_{\mathrm{ROH} / \mathrm{W}}-\log K_{\mathrm{CH} / \mathrm{W}}$ & $\mathrm{ROH} / \mathrm{W}$ & $\mathrm{CH} / \mathrm{W}$ & 1.944 & 0.311 & 1.633 \\
\hline$\Delta \log K_{\mathrm{MIP} / \mathrm{W}}=\log K_{\mathrm{MIP} / \mathrm{W}}-\log K_{\mathrm{CH} / \mathrm{W}}$ & IPM/W & $\mathrm{CH} / \mathrm{W}$ & 1.528 & 0.311 & 1.216 \\
\hline$\Delta \log K_{\mathrm{ROH} / \mathrm{W}}^{*}=\log K_{\mathrm{ROH} / \mathrm{W}}-\log K_{\mathrm{MIP} / \mathrm{W}}$ & $\mathrm{ROH} / \mathrm{W}$ & $\mathrm{IPM} / \mathrm{W}$ & 1.944 & 1.528 & 0.417 \\
\hline$\Delta \log K_{\mathrm{DMPC} / \mathrm{W}}=\log K_{\mathrm{DMPC} / \mathrm{W}}-\log K_{\mathrm{ROH} / \mathrm{W}}$ & $\mathrm{DMPC} / \mathrm{W}$ & $\mathrm{ROH} / \mathrm{W}$ & 2.394 & 1.944 & 0.450 \\
\hline$\Delta \log K_{\mathrm{DPPC} / \mathrm{W}}=\log K_{\mathrm{DPPC} / \mathrm{W}}-\log K_{\mathrm{ROH} / \mathrm{W}}$ & $\mathrm{DPPC} / \mathrm{W}$ & $\mathrm{ROH} / \mathrm{W}$ & 0.996 & 1.944 & -0.948 \\
\hline
\end{tabular}

a) $\Delta \log K=\log K_{1}-\log K_{2}$ 
tion coefficients shown in Table 2.

$\mathrm{CH}$ is an aprotic solvent that cannot form hydrogen bonds either as donor or acceptor. However, $\mathrm{ROH}$ by their hydroxyl group can be an acceptor and/or donor of hydrogen, and moreover their alkyl chain permits the structural immobilization of solutes owing to the tetrahedral microstructure adopted in saturation by this solvent, ${ }^{11,37)}$ in contrast to $\mathrm{CH}$ behavior. $\Delta \log K_{\mathrm{ROH} / \mathrm{W}}$ includes the contributions by hydrogen bonding and by structural immobilization to the partitioning. ${ }^{38)}$

Analogously, the parameter $\Delta \log K_{\mathrm{MIP} / \mathrm{W}}$ was calculated from the IPM/W and $\mathrm{CH} / \mathrm{W}$ partition coefficients. $\Delta \log$ $K_{\mathrm{MIP} / \mathrm{W}}$ allows estimation of the contribution of hydrogen bonding as an acceptor in IPM/W partitioning. The comparison of the parameter of Seiler $\left(\Delta \log K_{\mathrm{ROH} / \mathrm{W}}\right)$ with the parameter $\Delta \log K_{\mathrm{MIP} / \mathrm{W}}$ shows that octanol, in addition to contributing to BZC partitioning as an acceptor of hydrogen, may also contribute as a hydrogen donor, because the parameter of Seiler is larger than the $\Delta \log K_{\mathrm{MIP} / \mathrm{W}}$ value. Thus it could be defined a third parameter, $\Delta \log K^{*}{ }_{\mathrm{ROH} / \mathrm{W}}$, that compares the ROH/W and IPM/W partition coefficients to establish the contribution of the organic solvent as hydrogen donor to the partitioning.

The parameter $\Delta \log K_{\mathrm{DMPC} / \mathrm{w}}$ permits estimation of the contribution to partitioning by structural immobilization and by electrostatic effects depending on the phospholipid employed for the preparation of liposomes, according to the chain length and the possible presence of ionic charges in the polar heads of the phospholipids. ${ }^{38)}$ Table 4 shows that the effect due to immobilization is higher in DMPC liposomes than in DPPC liposomes. This behavior can be explained in terms of the liposome state according to the temperature, because in the range studied the DMPC liposomes are in a liquid crystal (fluid) state, whereas DPPC liposomes are in a gel (rigid) state.

\section{Conclusions}

From the values of $\Delta G_{\mathrm{w} \rightarrow 0}, \Delta H_{\mathrm{w} \rightarrow 0}$, and $\Delta S_{\mathrm{w} \rightarrow 0}$, it can be concluded that the transfer of BZC from aqueous media to all organic systems studied is spontaneous. The partitioning process in ROH and IPM is mainly driven by hydrogen bond interactions and by the disorder increase in the organic solvents. The partitioning in $\mathrm{CH}$ is driven by the disorder due to mixing of BZC and the organic solvent. In the case of the partitioning into DMPC liposomes, the process is probably driven by the interaction of BZC with the polar head of the phospholipid which produces immobilization of the solute, whereas in DPPC liposomes the process of transfer is mainly driven by the lipophilic immobilization of the solute in the phospholipidic bilayers. All the results of partitioning presented here confirm the lipophilic nature of BZC.

Acknowledgments We thank the Banco de la República and DINAINNational University of Colombia (NUC) for financial support, and also Merck Colombia S.A. for providing the octanol and the isopropyl myristate. In addition, we thank the Department of Pharmacy of NUC for facilitating the equipment and laboratories used.

\section{References}

1) Catterall W., Mackie K., "Goodman \& Gilman's. The Pharmacological
Basis of Therapeutics," 10th edn., Chapter 15, ed. by Hardman J. G., Limbird L. E., Gilman A. G., McGraw-Hill, New York, 2001.

2) Wang H. H., Earnest J., Limbacher H. P., Proc. Natl. Acad. Sci. U.S.A., 80, 5297-5301 (1983).

3) Peters H., Moll F., Arzneim.-Forsch./Drug Res., 45, 1253-1256 (1995).

4) Sanchez V., Arthur G. R., Strichartz G. R., Anesth. Analg., 66, 159165 (1987).

5) Fleming R., Guy R. H., Hadgraft J., J. Pharm. Sci., 72, 142-145 (1983).

6) Strichartz G. R., Sanchez V., Arthur G. R., Chafetz R., Martin D., Anesth. Analg., 71, 158-170 (1990).

7) Seeman P., Pharmacol. Rev., 24, 583-655 (1972).

8) Betageri G. V., Nayernama A., Habib M. J., Int. J. Pharm. Adv., 1, 310-319 (1996).

9) Leo A., Hansch C., Elkins D., Chem. Rev., 71, 525-616 (1971).

10) Diamond J. M., Katz Y., J. Membr. Biol., 17, 121-154 (1974).

11) Sangster J., "Octanol-Water Partition Coefficients: Fundamentals and Physical Chemistry," John Wiley \& Sons, Chichester, UK, 1997.

12) Barker N., Hadgraft J., Int. J. Pharmaceut., 8, 193-202 (1981).

13) Pozzo A. D., Donzelli G., Liggeri E., Rodriguez L., J. Pharm. Sci., 80, 54-57 (1991).

14) Jaiswal J., Poduri R., Panchagnula R., Int. J. Pharmaceut., 179, 129— 134 (1999).

15) Rogers J. A., Davis S. S., Biochim. Biophys. Acta, 598, 392-404 (1980).

16) Anderson N. H., Davis S. S., James M., Kojima I., J. Pharm. Sci., 72, $443-448(1983)$.

17) Ahmed M., Burton J. S., Hadgraft J., Kellaway I. W., J. Membr. Biol., 58, 181-189 (1981).

18) Ahmed A. M. S., Farah F. H., Kellaway I. W., Pharm. Res., 3, 119124 (1985).

19) Betageri G. V., Rogers J. A., Int. J. Pharmaceut., 36, 165-173 (1987).

20) Betageri G. V., Dipali S. R., J. Pharm. Pharmacol., 45, 931-933 (1993).

21) Go M. L., Ngiam T. L., Rogers J. A., Chem. Pharm. Bull., 43, 289294 (1995).

22) Go M. L., Ngiam T. L., Chem. Pharm. Bull., 45, 2055-2060 (1997).

23) Avila C. M., B.Sc. Thesis, National University of Colombia, 2001.

24) Bangham A. D., Phys. Chem. Lipids, 64, 275-285 (1993).

25) Lasic D. D., Sci. Med., 1996, (May/June), 34-43 (1996).

26) Beltrán O. C., Escobar M. J., Jiménez F., Barbosa H. J., Martínez F., Rev. Col. Cienc. Quím. Farm., 28, 117-122 (1999).

27) Cevc G., "Liposomes Technology," Vol. 1, Chapter 1, ed. by Gregoriadis G., CRC Press, Boca Raton, 1993.

28) Martin A. N., Bustamante P., Chun A. H. C., "Physical Pharmacy: Physical Chemical Principles in the Pharmaceutical Sciences," 4th edn., Lea \& Febiger, Philadelphia, 1993.

29) Florence A. T., Attwood D., "Physicochemical Principles of Pharmacy," 3rd edn., MacMillan Press, London, 1998.

30) Martínez F., Tello M., Gómez A., Rev. Col. Cienc. Quím. Farm., 29, $16-25$ (2000).

31) Budavari S., O’Neil M. J., Smith A., Heckelman P. E., Kinneary J. F., "The Merck Index, An Encyclopedia of Chemicals, Drugs, and Biologicals," 12th edn., Merck \& Co., Inc., Whitehouse Station, N.J., 1996.

32) Pinto L. M., Yokaichiya D. K., Fraceto L. F., de Paula E., Biophys. Chem., 87, 213-222 (2000).

33) Bevington P. R., "Data Reduction and Error Analysis for the Physical Sciences," McGraw-Hill Book Co., New York, 1969.

34) Koynova R., Caffrey M., Biochim. Biophys. Acta, 1376, 91-145 (1998).

35) Lipidat: Lipid thermotropic phase transition database, Ohio State University. Internet: <http://www.lipidat.chemistry.ohio-state.edu/>, 15 July 2001.

36) Seiler P., Eur. J. Med. Chem.-Chim. Ther., 9, 473-479 (1974).

37) DeBolt S. E., Kollman P. A., J. Am. Chem. Soc., 117, 5316-5340 (1995).

38) Martínez F., Ph.D. Thesis, National University of Colombia, 2001. 